\title{
sobre control de calidad del hormigón. La sifuación particular y el papel de los ensayos de calidad del hormigón endurecido
}

(Servicio de Investigaciones y Consejos Técnicos de la industria suiza del Cemento)

Journal de la Constrution de la Suisse Romande, n. ${ }^{\circ} 17$ (15-9-68), págs. 54-55

Si se consideran las diversas operaciones que jalonan la fabricación de un objeto, se distinguen en general claramente cuatro etapas:

a) Las materias primas dan nacimiento a productos intermedios.

b) Los productos intermedios dan nacimiento a materiales.

c) Un material da nacimiento a un esbozo.

d) Un esbozo da nacimiento a un objeto acabado.

Estas operaciones de fabricación, de "composición", de "dar forma" y de "acabado" están separadas unas de otras; no tienen relaciones fundamentales entre sí y son independientes tanto en el tiempo como en el espacio. Solamente el orden de sucesión de las operaciones es impuesto por su naturaleza.

Este desarrollo ordenado de las distintas etapas permite efectuar, de una manera sencilla, los controles cuya finalidad es obtener un objeto de cualidades exactamente conocidas. Gracias a su independencia en el espacio y en el tiempo, cada una de las etapas puede ser sometida a control. La ausencia de "tensión", en lo que se refiere al tiempo, permite almacenamientos intermedios que ofrecen la posibilidad de no librar un producto para la etapa siguiente hasta que se comprueba que cumple las condiciones exigidas. Se puede ver un efecto retroactivo de estos controles, en el sentido de que los resultados de ensayos rápidos efectuados sobre un producto permiten influir, y corregir, la fabricación de este último y obtener así una regularidad máxima de su calidad. La construcción en hormigón no sigue desgraciadamente este cómodo ordenamiento. Las etapas "b" y "c" están fusionadas y es frecuente que una parte de las etapas "a" y " $d$ " coincida igualmente con la operación principal. Las cuatro operaciones iguales del caso normal se concentran, para la producción del hormigón, en una operación central importante con pequeñas operaciones 
inicial y final. Los principios y las posibilidades de los controles de calidad se separan de la misma manera del caso normal. Al lado de estas influencias particulares debidas al proceso de fabricación, hay otras imputables a las propiedades del material "hormigón" mismo.

El hormigón es un material muy heterogéneo. Está constituido por diferentes áridos y pasta de cemento que tienen todos propiedades particulares. Es, por tanto, sensiblemente diferente de la mayor parte de los otros materiales, lo que hace más difíciles los controles de calidad o, más exactamente, da menos valor a los resultados de los ensayos efectuados.

Si se comparan dos cubos de hormigón de $20 \mathrm{~cm}$ de arista, uno con árido máximo $100 \mathrm{~mm}$ y el otro con árido máximo $10 \mathrm{~mm}$, se comprende bien que, para el hormigón de árido grueso, el riesgo de que una medida de resistencia sea demasiado baja es mucho mayor que para el hormigón de árido menudo.

Cuando la relación árido máximo/dimensión de la probeta aumenta, la dispersión de los resultados de ensayo aumenta también, y al mismo tiempo el valor útil de las medidas disminuye. Si las propiedades de una probeta de hormigón dependen de algunos elementos del árido solamente, los resultados de ensayo dependerán mucho más de las resistencias, de las formas y de las posiciones individuales de estos elementos.

Esta estructura y el modo de fabricación del hormigón son características muy particulares que no se encuentran apenas en otros materiales. Estas particularidades condicionan los procedimientos y métodos de determinación de la calidad.

¿Cuáles son, en estas condiciones, los problemas principales que plantean los controles de la calidad?

1. La toma de muestras no se puede hacer más que en un momento bien determinado, inmediatamente después de amasado el hormigón. Todo el mundo está entonces plenamente ocupado, existe el riesgo de que la toma no se realice con arreglo a todas las reglas y que la probeta no se confeccione con todo el cuidado que fuera de desear.

2. Los ensayos propiamente dichos no son en general ejecutados en la misma obra o en sus cercanías. Las probetas no pueden ser, por consiguiente, conservadas en condiciones determinadas y constantes hasta el momento de los ensayos, lo que las deja a merced de numerosas influencias incontrolables.

3. Debido a la lentitud del endurecimiento del hormigón, los resultados de ensayo son conocidos demasiado tarde. No es posible una influencia retroactiva sobre la fabricación del hormigón, de la misma manera que no es posible suministrar un material controlado previamente. Cuando llegan los primeros resultados de ensayo, la obra está ya terminada y las eventuales correcciones no serían posibles más que al precio de operaciones muy costosas.

4. ${ }^{\circ}$ La heterogeneidad del hormigćn y la gran dispersión de los resultados de ensayo que de ellos se desprenden exigen que se tomen varias muestras de cada hormigón. No se puede hacer una idea válida de la calidad más que si se considera la media de los resultados de una serie de varios ensayos. Las muestras de cada serie deben ser comparables entre sí. Deben ser tomadas en el mismo sitio, en un espacio de tiempo limitado en el curso del cual los materiales permanezcan los mismos y la composición granulométrica sea también la misma. 
Estos puntos fundamentales de la técnica de ensayo, a los que se añaden otros en ciertos casos, entrañan las dos consecuencias siguientes:

- Los controles no pueden servir para mejorar de manera inmediata la calidad del hormigón.

- La información que se puede sacar de los ensayos no ofrece una certeza absoluta.

Así el ensayo de los materiales no puede tener más que un rigor limitado. Sus resultados y las conclusiones que de ellos se puedan deducir no tienen para el hormigón la misma significación que para el metal, la cerámica, el vidrio o los materiales sintéticos.

Los ensayos no permiten modificar directamente las propiedades del material, sino únicamente por experiencia, preparar buenos hormigones en el futuro. Indican, por ejemplo, que un cierto hormigón tiene una resistencia a la compresión de $423 \mathrm{~kg} / \mathrm{cm}^{2}$ a 28 días. Se deduce de ello que un hormigón de la misma composición y sometido a las mismas condiciones de conservación tendrá la misma resistencia. Los ensayos de hormigón no tienen pues verdadero valor más que si es posible dar al mismo tiempo la composición exacta de este hormigón y preparar posteriormente hormigones de la misma composición. Según las normas suizas para la fabricación del hormigón (SIA n. ${ }^{\circ}$ 162), un hormigón es definido por su composición granulométrica y por su dosificación en cemento. Se conocen desde hace tiempo fórmulas que permiten calcular de antemano la resistencia de un hormigón con ayuda del factor agua/cemento. Estas fórmulas son útiles, puesto que los ensayos de hormigón no permiten más que una comprobación posterior de la resistencia.

Debido a la heterogeneidad del hormigón, los resultados de ensayos aislados no son nunca determinantes; es siempre necesario acompañarlos de la media de otros varios resultados. Los resultados son influenciados, no solamente por las irregularidades de la composición del hormigón, sino también por ciertos factores que intervienen en el endurecimiento y que son todavía mal conocidos. Estos últimos hacen que los resultados sean tanto más dispersos y menos precisos cuanto más joven sea el hormigón en el momento de los ensayos.

Si se quiere acortar el tiempo entre la fabricación del hormigón y los ensayos, hay que esperar una mayor dispersión de los resultados.

En resumen, si en las cadenas de producción en general de los ensayos de los materiales permiten corregir la fabricación, no es éste el caso de la fabricación del hormigón. Para obviar este inconveniente, es obligado respetar escrupulosamente las reglas de la puesta en obra y la composición prescrita sobre la base de ensayos previos y comprobados, en fin de cuentas, por los ensayos de rutina.

La comprobación es siempre la parte improductiva y pasiva de los ensayos de calidad. Su parte activa está constituida por la previsión de las resistencias y vale la pena realizarla para describir exactamente los hormigones que hayan sido objeto de los ensayos previos y para reproducirlos fielmente. 